\title{
The effect of nebivolol on the production of nitric oxide induced by bacterial lipopolysaccharide and peptidoglycan in mice
}

\author{
Fadi El-Rami ${ }^{1}$, Hampartsoum Barsoumian ${ }^{1}$, Joseph Simaan ${ }^{2}$, Alexander M. Abdelnoor ${ }^{1 *}$ \\ ${ }^{1}$ Department of Microbiology and Immunology, Faculty of Medicine, American University of Beirut, Beirut, Lebanon; \\ *Corresponding Author: aanoor@aub.edu.lb \\ ${ }^{2}$ Department of Pharmacology and Therapeutics, Faculty of Medicine, American University of Beirut, Beirut, Lebanon
}

Received 25 June 2010; revised 18 July 2010; accepted 2 August 2010.

\begin{abstract}
Nitric oxide (NO) plays a pivotal role in maintaining balance of physiological events in many systems including the autonomic, cardiovascular, hematological, and pulmonary systems. Lipopolysaccharide (LPS) and peptidoglycan (PGN), components of the outer cell membranes of Gram-negative bacteria and cell walls of Gram-positive bacteria respectively, are incriminated in NO-induced septic shock. Nebivolol is a third generation $\beta 1$-adrenoceptor blocker with a vasodilatory property attributed to enhanced availability of nitric oxide and reduction of cellular oxidative stress through an unknown mechanism. The current study explored the hypothesis that if nebivolol enhances the availability of NO, pretreatment with nebivolol may enhance production of NO in response to subsequent treatment with LPS and $P G N$, an observation that may have relevance in clinical septic shock. Groups of female BALB/c mice each containing 12 mice (6-8 weeks old) were injected intraperitoneally with LPS (30 $\mu \mathrm{g} / \mathrm{mouse}), \mathrm{PGN}$ (100 $\mu \mathrm{g} / \mathrm{mouse})$, nebivolol (0.25 $\mu \mathrm{g} / \mathrm{g}, 0.35 \mu \mathrm{g} / \mathrm{g}, 0.7 \mu \mathrm{g} / \mathrm{g})$, LPS and nebivolol $(0.25 \mu \mathrm{g} / \mathrm{g})$, LPS and nebivolol $(0.35 \mu \mathrm{g} / \mathrm{g})$, LPS and nebivolol $(0.7 \mu \mathrm{g} / \mathrm{g}), \mathrm{PGN}$ and nebivolol $(0.25 \mu \mathrm{g} / \mathrm{g})$, PGN and nebivolol $(0.35 \mu \mathrm{g} / \mathrm{g})$. One group of mice was injected with saline and another served as control. Three mice from each group were bled 1, 3, 6 and 9 hours post-injection, the blood was pooled and the nitrite serum levels, reflecting NO concentration, were determined using Greiss reagent. The following results were obtained: 1) Treatment with saline did not induce NO production; 2) LPS induced NO production to a maximal limit of $545 \%$ at 9
\end{abstract}

hours as compared to treatment with saline; 3 ) PGN did not induce NO production; 4) Nebivolol at most doses and periods (7 out of 10 determinations) increased NO production over a range of $18-110 \%$ as compared to treatment with saline; 5) Nebivolol enhanced LPS-induced production of NO by $58 \%$ at a dose of $0.7 \mu \mathrm{g} / \mathrm{gm}$ at 9 hours. It is concluded that nebivolol induces NO production. At low doses nebivolol initially appeared to have a suppressive or no effect on NO production induced by LPS. Increase in the dose of nebivolol resulted in augmentation of LPS-induced production of NO. $P G N$, in the dose tested, did not have an effect on NO production.

Keywords: Nebivolol; Peptidoglycan; Lipopolysaccharide; Nitric Oxide;

$\beta 1$-Adrenoceptor Blocker

\section{INTRODUCTION}

Since the early report by Furchgott and Zawadzki in 1980 that the endothelium produces a vasodilator substance, initially referred to as the endothelium-derived relaxing factor, later demonstrated to be $\mathrm{NO}$, extensive research revealed that $\mathrm{NO}$ was a short-lived mediator of numerous physiological as well as pathophysiological phenomena [1]. NO is synthesized by vascular endothelium, macrophages, neutrophils, Kupffer cells, brain cells and other cell types through the enzymatic effect of NO synthase on L-arginine [2]. NO, a very small lipophilic molecule with an ultra short half-life less than 5 seconds in biological tissues is a pleiotropic molecule that is indispensable for various physiological functions [3]. In the vascular bed, NO is a prominent vasodilator that relaxes smooth muscle, a potent inhibitor of platelet 
aggregation, and a major mediator of proliferation of vascular smooth muscle and endothelial cells via a cyclic GMP-independent mechanism [4-6]. Furthermore, some studies showed that NO reduces cardiomyocyte apoptosis and oxygen consumption despite reduced blood flow in patients $[7,8]$. NO is a mediator of defense mechanisms including its cytotoxic role against foreign cells through functional disruption, and in tumor cells through DNA damage and p53 accumulation. However, elevated NO levels have deleterious effects. NO leads to increased pain perception through stimulation of pain-mediating sensory nerves, overproduction of peroxynitrite with negative effects on proteins and cell function, S-nitrosylation of proteins such as transcription factors, signaling kinases, ion channels and TGF- $\beta$, which elicits conformational modifications leading to loss of function [9-12].

Peptidoglycan (PGN), a constituent of the bacterial cell wall, is a polymer of $\mathrm{N}$-acetylglucosamine and $\mathrm{N}$ acetylmuramic acid residues. Lipopolysaccharide (LPS) is an amphipathic component of Gram-negative bacterial outer membrane consisting of 3 parts: the O-antigen (O-polysaccharide), the core polysaccharide and lipid A [13]. Both LPS and PGN are believed to contribute to hypotension and shock in bacteremias. PGN engages Toll-like receptor 2 (TLR2) and activates the myeloid differentiation factor 88 (MyD88)-independent pathway and LPS engages TLR4 that results in activation of both the MyD88-dependent and independent pathways. Both pathways lead eventually to an inflammatory response, mainly through the production of pro-inflammatory cytokines and inducible nitric oxide synthase (iNOS) [14-16].

Nebivolol is a novel third generation $\beta 1$-adrenoceptor blocker [17-19] advocated for the treatment of hypertension. It is unique among all $\beta 1$-adrenoceptor blockers in that it possesses a vasodilatory property attributed to synthesis of NO [20,21] as well as to increasing NO bioavailability by decreasing the oxidative stress [22-26]. In addition, Ladage et al. [27] reported that the endothelium-dependent increase in NO induced by nebivolol was due to stimulation of $\beta_{3}$-adrenoceptors and estrogen receptors. Clinically, nebivolol has been shown to protect the heart from ischemia, arrhythmia and myocardial infarction through $\mathrm{NO}$, including limiting oxygen consumption and maintaining cardiac contraction even with a reduced blood flow, in addition to minimizing cardiomyocyte apoptosis [28-30].

In bacteremias, bacterial cells release some of their constituents such as LPS, lipoteichoic acid and PGN. These constituents stimulate a number of cell types to produce NO. The current study was undertaken to explore the effect of nebivolol on PGN- and LPS-induced
NO production, reflected by determination of serum nitrite concentration.

\section{MATERIALS AND METHODS}

\subsection{Study Protocol}

Experiments were performed on 132 female BALB/c mice divided into 10 groups of 12 mice each and 2 groups of 6 mice each, treated with intraperitoneal injections of either saline, LPS, PGN, nebivolol or combinations as summarized in Table 1. All the groups of mice, except groups 7 and 10, were bled 1, 3, 6 and 9 hours post-treatment. Prior to bleeding, mice were anesthetized by an intraperitoneal injection of ketamine and xylazine. The blood of 3 mice from each group at each time interval was pooled, allowed clotting and the serum was separated and stored at $4{ }^{\circ} \mathrm{C}$ for nitrate/nitrite measurement. Groups 7 and 10 were bled at 6 and 9 hours post-treatment. Serum concentration of nitric oxide was indirectly measured using the Greiss reagent which determines the concentration of nitrite $\left(\mathrm{NO}_{2}^{-}\right)$and the nitrate $\left(\mathrm{NO}_{3}{ }^{-}\right)$, the final breakdown products of nitric oxide. The Greiss reagent was used according to the manufacturer's instructions (Sigma Chemicals co., MO, USA). NO has an ultra short half-life in blood that does not exceed 5 seconds. It dissociates into two final end products, namely nitrite $\left(\mathrm{NO}_{2}{ }^{-}\right)$and nitrate $\left(\mathrm{NO}^{-}\right)$. Greiss reagent changes nitrates to nitrites and measures the nitrite concentration through a colorimetric reaction, the concentration of nitrite reflecting the concentration of NO. Spectrophotometric readings were done at a wavelength 490nm using a microplate reader. Assays for the determination of nitrate and nitrite were run twice as each sample of blood was pooled from 3 mice that received the same treatment at the same time interval. The average of the two determinations was taken as a reflection of NO concentration and the standard deviation of the two determinations was calculated indicated reproducibility of the analysis. Comparisons between different groups of mice and at different time intervals were considered significant when there was no overlap between the means and standard deviations.

\subsection{Drugs and Reagents Used}

LPS from Salmonella enterica serovar Minnesota (Sigma Chemicals co., MO, USA, prepared as suspendsion of $30 \mu \mathrm{g} / 0.5 \mathrm{ml}$ ); PGN from Bacillus subtilis (Sigma Chemicals co., MO, USA, prepared as a suspension of $100 \mu \mathrm{g} / 0.5 \mathrm{ml}$ ); nebivolol (Cipla, India, prepared as dilutions of $0.25 \mu \mathrm{g} / \mathrm{g}-0.7 \mu \mathrm{g} / \mathrm{g}$ ); ketamine (Panpharma, France, prepared as dilution of $6 \mathrm{mg} / 0.5 \mathrm{ml}$ ); xylazine (Interchemie, Holland, prepared as dilution of 
Table 1. Dose of preparations injected to different groups of mice.

\begin{tabular}{cccc}
\hline Group Number & Intraperitoneal Injection of Agent & Number of mice & Injection volume \\
\hline Group 1 & Negative control & 12 & $0.5 \mathrm{ml}$ \\
Group 2 & Saline (vehicle used to solutions) & 12 & $0.5 \mathrm{ml}$ \\
Group 3 & LPS $(30 \mu \mathrm{g} /$ mouse $)$ & 12 & $0.5 \mathrm{ml}$ \\
Group 4 & PGN $(100 \mu \mathrm{g} /$ mouse $)$ & 12 & $0.5 \mathrm{ml}$ \\
Group 5 & $\mathrm{n}(0.25 \mu \mathrm{g} / \mathrm{g})$ & 12 & $0.5 \mathrm{ml}$ \\
Group 6 & $\mathrm{n}(0.35 \mu \mathrm{g} / \mathrm{g})$ & 12 & $0.5 \mathrm{ml}$ \\
Group 7 & $\mathrm{n}(0.7 \mu \mathrm{g} / \mathrm{g})$ & 6 & $0.5 \mathrm{ml}$ \\
Group 8 & LPS $(30 \mu \mathrm{g} / \mathrm{mouse})+\mathrm{n}(0.25 \mu \mathrm{g} / \mathrm{g})$ & 12 & $0.5 \mathrm{ml}$ \\
Group 9 & LPS $(30 \mu \mathrm{g} / \mathrm{mouse})+\mathrm{n}(0.35 \mu \mathrm{g} / \mathrm{g})$ & 12 & $0.5 \mathrm{ml}$ \\
Group 10 & LPS $(30 \mu \mathrm{g} / \mathrm{mouse})+\mathrm{n}(0.7 \mu \mathrm{g} / \mathrm{g})$ & 6 & $0.5 \mathrm{ml}$ \\
Group 11 & PGN $(100 \mu \mathrm{g} /$ mouse $)+\mathrm{n}(0.25 \mu \mathrm{g} / \mathrm{g})$ & 12 & $0.5 \mathrm{ml}$ \\
Group 12 & PGN $(100 \mu \mathrm{g} /$ mouse $)+\mathrm{n}(0.35 \mu \mathrm{g} / \mathrm{g})$ & 12 & $0.5 \mathrm{ml}$ \\
\hline
\end{tabular}

n: nebivolol; LPS: lipopolysaccharide; PGN: peptidoglycan.

$0.6 \mathrm{mg} / 0.5 \mathrm{ml}$ ); Greiss reagent (Sigma Chemicals co., MO, USA). Chemicals were dissolved in pyrogen free saline, except for the anesthetics which were dissolved in pyrogen free water. All solvents were confirmed pyrogen free by the Limulus Amebocyte Lysate (LAL) test.

\section{RESULTS}

The changes in the serum concentration of nitrites ( $\mu$ mole/l) in response to various treatments and time intervals are summarized in Table 2.

\subsection{Untreated and Saline-Treated Groups of Mice}

NO levels in mice that were untreated or injected with saline were approximately the same (Table 2).

\subsection{Group of Mice Treated with Nebivolol}

Out of 10 assays in different doses at different time intervals, nebivolol increased the nitrate/nitrite production in 7 assays over a range of $18-170 \%$ as compared to saline treated group (Tables 2,3, Figure 1).

\subsection{Group of Mice Treated with LPS Alone}

As compared to the saline-treated group, there was an increase with nitrate/nitrite concentration of $93 \%, 71 \%$, $356 \%$ and $545 \%$ at time intervals 1, 3, 6 and 9 hours respectively (Tables 2,4, Figure 2).

\subsection{Group of Mice Treated with PGN Alone}

PGN had an inconsistent effect on nitrate/nitrite production ranging from $-27 \%$ to $+29 \%$ at various time intervals, as compared to saline treated group. (Tables 2, 4, Figure 2).

\subsection{Group of Mice Treated with LPS + Nebivolol}

Out of 10 assays in different doses at different time intervals, there was a decrease or no change in nitrate/ nitrite production in 9 assays, ranging from $-4 \%$ to $-65 \%$ as compared to respective values in response to treatment with LPS alone. However, at a dose of nebivolol of $0.7 \mu \mathrm{g} / \mathrm{gm}$ and an interval of 9 hours, there was an increase in nitrate/nitrite production of $58 \%$ as compared to the respective value after treatment with LPS alone, implying that LPS-induced NO production is inhibited by nebivolol in lowest doses at short intervals of exposure and is potentiated at high doses and long interval of exposure (Tables 2,5, Figure 3).

\subsection{Groups of Mice Treated with PGN + Nebivolol}

Treatment with nebivolol in different doses and at different intervals produced an inconsistent effect of PGN-induced effect on nitrate/nitrite production varying from no change in two assays, a decrease of $-13 \%$ to $-18 \%$ in two assays and an increase in four assays of 
Table 2. Total concentration of nitrite in serum, reflecting serum concentration of nitric oxide, under control conditions and in response to various treatments at different time intervals post-challenge.

\begin{tabular}{cccccc}
\hline & & \multicolumn{3}{c}{ Concentration of nitrite in serum $(\mu \mathrm{mol} / \mathrm{L})$} \\
\hline Series & Hours post-treatment & 1 & 3 & 6 & 9 \\
1 & Control & $41.5 \pm 2.4$ & $43.9 \pm 2.4$ & $51.1 \pm 0$ & $46.3 \pm 2.4$ \\
2 & Saline & $31.2 \pm 4.1$ & $48.0 \pm 0$ & $44.9 \pm 2.4$ & $32.9 \pm 2.4$ \\
3 & LPS: $30 \mu \mathrm{g} / 0.5 \mathrm{ml}$ & $60.4 \pm 11.5$ & $82.3 \pm 16.5$ & $204.9 \pm 17.4$ & $212.9 \pm 9.3$ \\
4 & PGN: $100 \mu \mathrm{g} / 0.5 \mathrm{ml}$ & $39.8 \pm 4.5$ & $34.7 \pm 2.2$ & $29.9 \pm 5.4$ & $40.9 \pm 10.1$ \\
5 & $\mathrm{n}: 0.25 \mu \mathrm{g} / \mathrm{g}$ & $37.5 \pm 2.4$ & $39.2 \pm 1.0$ & $43.8 \pm 2.2$ & $42.1 \pm 2.9$ \\
6 & $\mathrm{n}: 0.35 \mu \mathrm{g} / \mathrm{g}$ & $44.7 \pm 2.7$ & $58.8 \pm 4.7$ & $74.9 \pm 10.7$ & $88.8 \pm 7.3$ \\
7 & $\mathrm{n}: 0.7 \mu \mathrm{g} / \mathrm{g}$ & $\mathrm{ND}$ & $\mathrm{ND}$ & $32.6 \pm 1.0$ & $39.3 \pm 3.3$ \\
8 & $\mathrm{LPS}+\mathrm{n}: 0.25 \mu \mathrm{g} / \mathrm{g}$ & $29.1 \pm 1.7$ & $28.7 \pm 1.2$ & $113.6 \pm 5.7$ & $211.7 \pm 8.0$ \\
9 & $\mathrm{LPS}+\mathrm{n}: 0.35 \mu \mathrm{g} / \mathrm{g}$ & $57.4 \pm 10.0$ & $63.3 \pm 1.3$ & $175.3 \pm 2.2$ & $202.0 \pm 11.9$ \\
10 & $\mathrm{LPS}+\mathrm{n}: 0.7 \mu \mathrm{g} / \mathrm{g}$ & $\mathrm{ND}$ & $\mathrm{ND}$ & $197.0 \pm 7.7$ & $335.7 \pm 7.8$ \\
11 & PGN $+\mathrm{n}: 0.25 \mu \mathrm{g} / \mathrm{g}$ & $39.2 \pm 3.9$ & $40.2 \pm 5.7$ & $34.7 \pm 1.2$ & $34.0 \pm 3.6$ \\
12 & PGN $+\mathrm{n}: 0.35 \mu \mathrm{g} / \mathrm{g}$ & $33.3 \pm 4.7$ & $39.9 \pm 3.6$ & $26.1 \pm 1.3$ & $40.15 \pm 1.2$ \\
\hline
\end{tabular}

Serum nitrite concentrations were analyzed in duplicate and the average of the two determinations was taken as a reflection of NO concentration and the standard deviation of the two determinations indicated reproducibility of the analysis. LPS: lipopolysaccharide; PGN: peptidoglycan; n: nebivolol; ND: not determined.

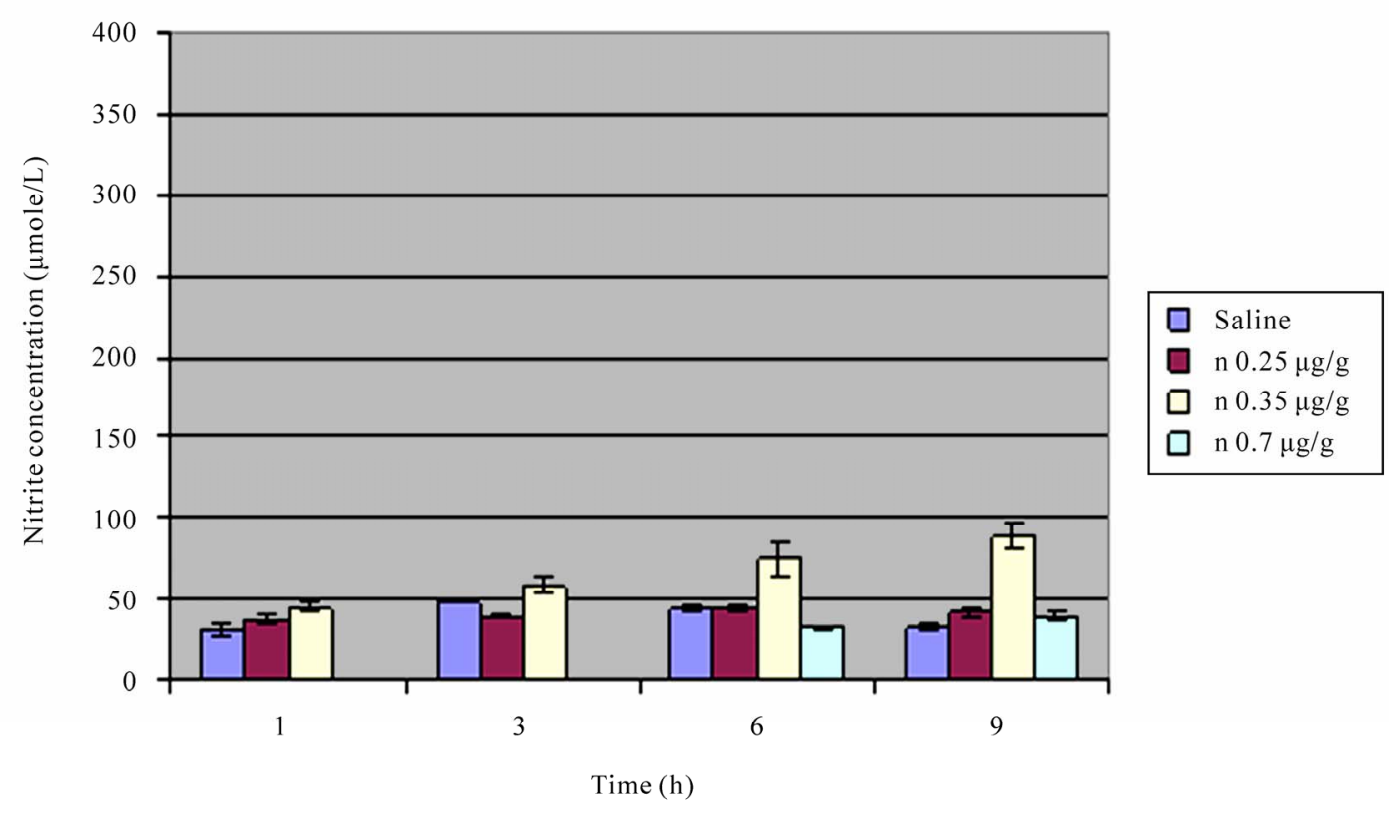

Figure 1. Nitrite levels, reflecting NO levels, at 1, 3,6 and 9 hours after injection with either saline or nebivolol (n). Columns represent mean of duplicate analysis and the bars standard deviation of the duplicate analysis. Differences between concentrations of nitrite were considered significant when the means and the standard deviations did not overlap. n: nebivolol. 
Table 3. Percentage change in nitrite concentration in response to treatment with nebivolol as compared to treatment with saline at different time intervals post-challenge.

\begin{tabular}{ccccc} 
Dose of nebivolol $(\mu \mathrm{g} / \mathrm{g})$ & Percent change at hour 1 & Percent change at hour 3 & Percent change at hour 6 & Percent change at hour 9 \\
\hline 0.25 & +19 & -18 & -2.3 & +27 \\
0.35 & +45 & +23 & +67 & +170 \\
0.7 & ND & ND & -27 & +18 \\
\hline
\end{tabular}

$\mathrm{ND}=$ not determined

Table 4. Percentage change in nitrite concentration in response to treatment with LPS and PGN as compared to treatment with saline at different time intervals post-challenge.

\begin{tabular}{|c|c|c|c|c|c|}
\hline \multicolumn{2}{|c|}{ Dose ( $\mu \mathrm{g} /$ mouse $)$} & \multirow{2}{*}{ Percent change at hour 1} & \multirow{2}{*}{ Percent change at hour 3} & \multirow{2}{*}{ Percent change at hour 6} & \multirow{2}{*}{ Percent change at hour 9} \\
\hline LPS & PGN & & & & \\
\hline 30 & 0 & +93 & +71 & +356 & +545 \\
\hline 0 & 100 & +29 & -27 & -33 & +24 \\
\hline
\end{tabular}

LPS: lipopolysaccharide, PGN: peptidoglycan.

Table 5. Percentage change in nitrite concentration in response to treatment with LPS and nebivolol in different doses, as compared to treatment with LPS alone at different time intervals post-challenge.

\begin{tabular}{|c|c|c|c|c|c|}
\hline \multicolumn{2}{|c|}{ Dose } & \multirow[b]{2}{*}{ Percent change at hour 1} & \multirow[b]{2}{*}{ Percent change at hour 3} & \multirow[b]{2}{*}{ Percent change at hour 6} & \multirow[b]{2}{*}{ Percent change at hour 9} \\
\hline $\begin{array}{c}\text { LPS } \\
\text { ( } \mu \mathrm{g} / \text { mouse) }\end{array}$ & $\mathrm{N}(\mu \mathrm{g} / \mathrm{g})$ & & & & \\
\hline 30 & 0.25 & -51 & -65 & -44 & 0 \\
\hline 30 & 0.35 & -5 & -23 & -16 & -5 \\
\hline 30 & 0.7 & ND & ND & -4 & +58 \\
\hline
\end{tabular}

$\mathrm{ND}=$ not determined; $\mathrm{N}=$ nebivolol; LPS: lipopolysaccharide .

$14 \%$ to $17 \%$ in different concentrations and time intervals as compared to respective values of treatment with PGN alone (Tables 2,6, Figure 4).

\section{DISCUSSION}

Nebivolol is a novel third generation $\beta 1$-adrenoceptor blocker [17-20] advocated for the treatment of hypertension. It is unique among all $\beta 1$-adrenoceptor blockers in that it possesses a vasodilatory property attributed to synthesis of $\mathrm{NO}[21,22]$ as well as to increasing $\mathrm{NO}$ bioavailability by decreasing the oxidative stress [23-27]. The observation that nebivolol increases the concentration of nitrite in 7 out of 10 as- says using different doses and at different time intervals, reflecting an increase in the NO levels, is confirmatory to observations reported by others [31-33].

LPS and PGN have been associated with increased production of NO during sepsis, where NO has been a major contributor to vascular collapse, a major cause of mortality in septic shock cases [34,35]. LPS but not PGN induced NO synthesis. This can be attributed partly to the different signaling pathways induced by each. There are at least two pathways that LPS activates, both of which lead to the production of NO. In the first, LPS engages TLR4 expressed by macrophages and neutronphils. As a result 2 intracellular signaling pathways, the MyD88-dependent and independent pathways are activated and lead to the production of pro-inflammatory cytokines and NO [36-40]. In the second pathway, LPS induces the production of gamma interferon which in turn interacts with its receptor expressed on several cell types [41]. The intracellular events that follow lead to the activation of the transcription factor, IRF-1, and production of NO. In support of these results, previous studies have shown that LPS, rather than PGN, induced effectively the cytokine expression machinery (TNF- $\alpha$, IL-1 $\alpha$, IL-12, IL-23, IFN- $\gamma$, CCL-2, CCL-5) 3 hours after LPS treatment shifting to a Th1 response as evidenced by the high IFN- $\gamma / \mathrm{IL}-4$ ratio and by the immense 
delayed type hypersensitive response, while PGN favored the Th2 type [42]. Moreover, Fahmi et al. [43] have shown that lipoteichoic acid rather than PGN is the potent inducer of NO upon severe infection with Grampositive bacteria and that PGN augmented the lipoteichoic acid-NO inducing activity. It is worth noting that Ida et al. [44] reported that propanolol, a beta adrenergic receptor antagonist, did not influence cytokine release by lipoteichoic acid.

Nebivolol at doses 0.25 and $0.35 \mu \mathrm{g} / \mathrm{g}$ given in combination with LPS had no, or a suppressive effect on NO production induced by LPS. Arai et al. [45] reported that beta adrenergic receptor antagonists (ICI-188551, betaxolol, timolol and metipranolol) did not influence NO production induced by LPS. However, nebivolol at a dose $0.7 \mu \mathrm{g} / \mathrm{g}$ potentiated NO production induced by LPS at 9 hours post-injection, implying that the effect of nebivolol on LPS-induced NO production is dose and time-dependent. These results could in part be explained by the study of Broeder et al. [18] who reported that nebivolol does not induce the production of NO. Rather, its metabolites do so. It appears that a time factor is involved, taking about 9 hours for the production of metabolites which contribute to the delayed effect of nebivolol. It can be hypothesized that intact nebivolol has a suppressive effect on NO production induced by LPS, and its metabolites that take about 9 hours to be formed enhance NO production induced by LPS.

Table 6. Percentage change in nitrite concentration in response to treatment with PGN and nebivolol in different doses, as compared to treatment with PGN alone at different time intervals post-challenge.

\begin{tabular}{cccccc}
\hline \multicolumn{2}{c}{ Dose } & & & \\
\hline $\begin{array}{c}\text { PGN } \\
(\mu \mathrm{g} / \text { mouse })\end{array}$ & $\mathrm{N}(\mu \mathrm{g} / \mathrm{g})$ & Percent change at hour 1 & Percent change at hour 3 & Percent change at hour 6 & Percent change at hour 9 \\
\hline 100 & 0.25 & 0 & +14 & +17 & +17 \\
100 & 0.35 & -18 & +14 & -13 & 0 \\
100 & 0.7 & $\mathrm{ND}$ & $\mathrm{ND}$ & $\mathrm{ND}$ & $\mathrm{ND}$ \\
\hline
\end{tabular}

$\mathrm{ND}=$ not determined; $\mathrm{N}$ = nebivolol; LPS: lipopolysaccharide.

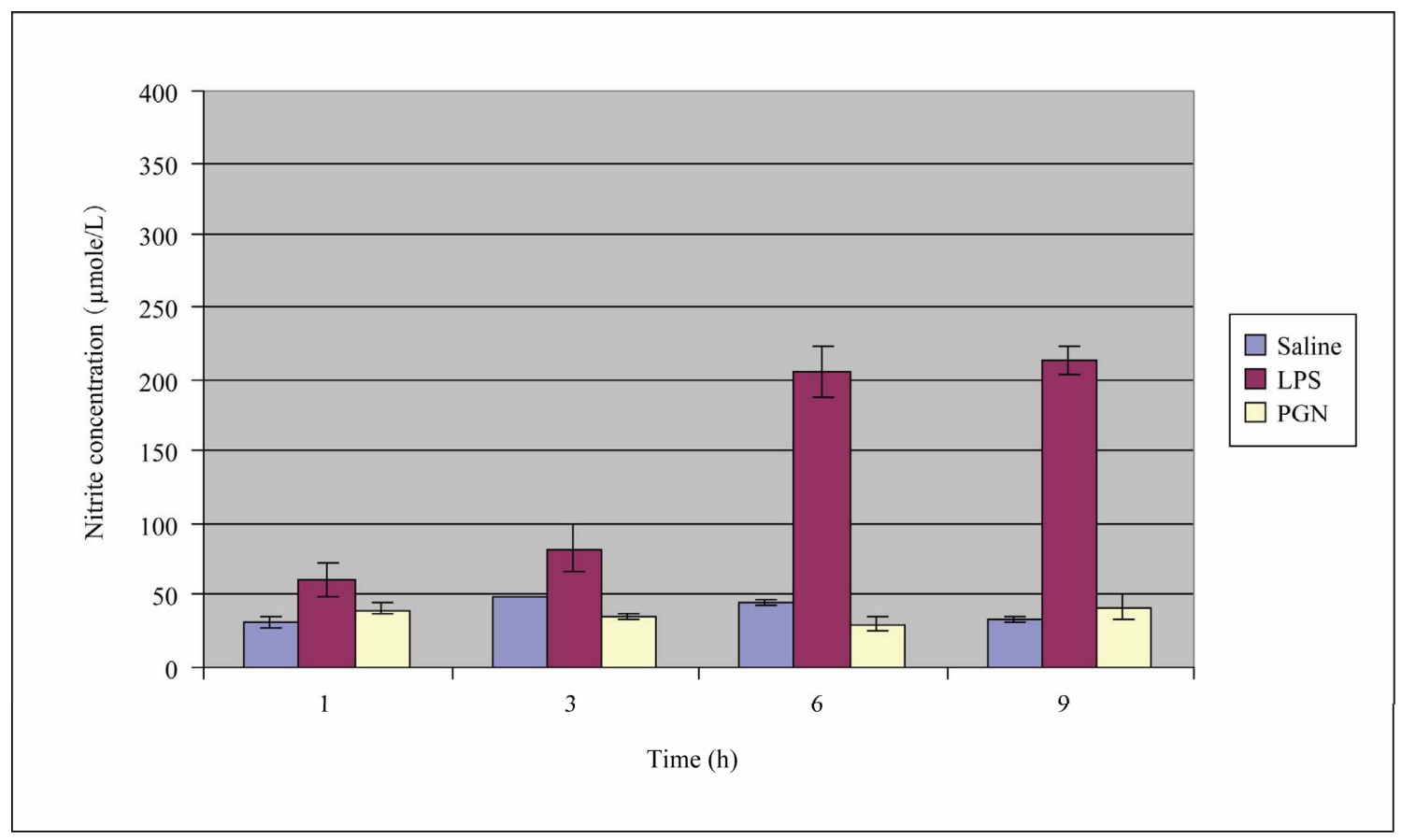

Figure 2. Nitrite levels, reflecting NO levels, at 1, 3,6 and 9 hours after injection of saline, LPS and PGN. Columns represent mean of duplicate analysis and the bars standard deviation of the duplicate analysis. Differences between concentrations of nitrite were considered significant when the means and the standard deviations did not overlap. LPS: lipopolysaccharide (30 $\mu \mathrm{g} /$ mouse); PGN: peptidoglycan (100 $\mu \mathrm{g} / \mathrm{mouse})$. 


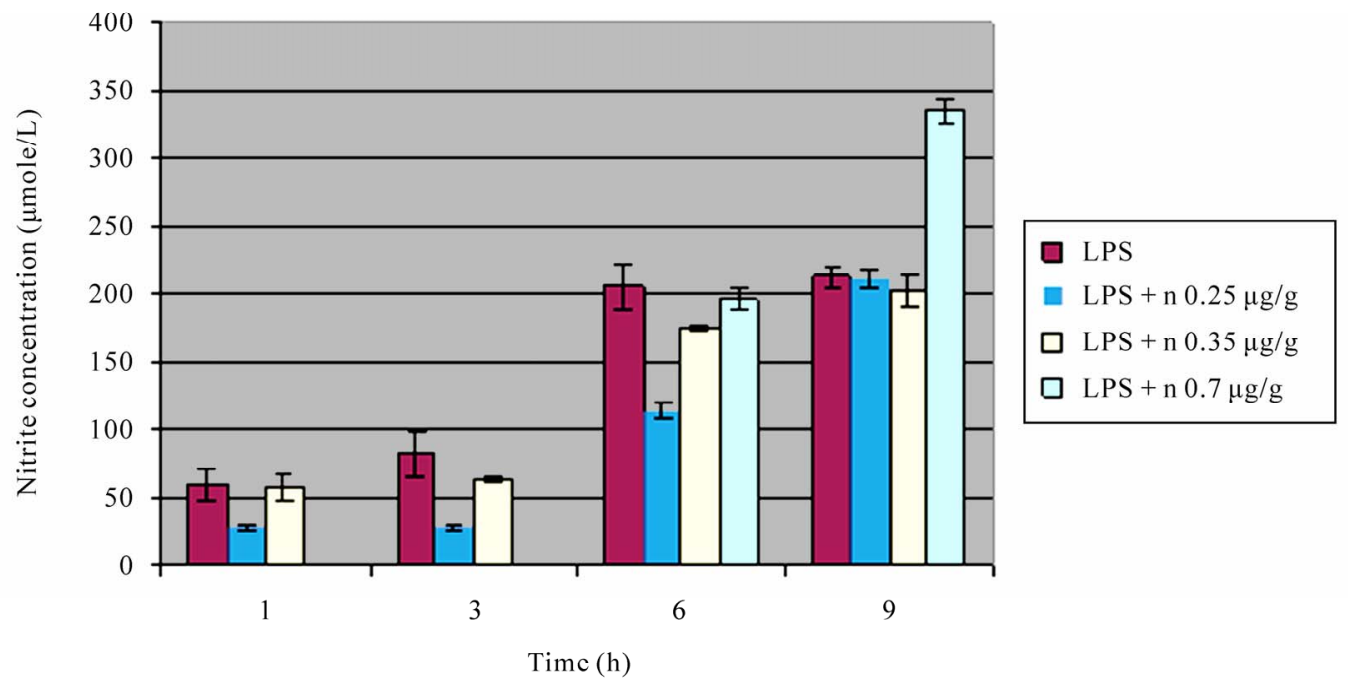

Figure 3. Nitrite levels, reflecting NO levels, at 1, 3, 6 and 9 hours after injection of LPS or LPS with nebivolol (n). Columns represent mean of duplicate analysis and the bars standard deviation of the duplicate analysis. Differences between concentrations of nitrite were considered significant when the means and the standard deviations did not overlap. LPS: lipopolysaccharide( $30 \mu \mathrm{g} /$ mouse $)$; n: nebivolol.

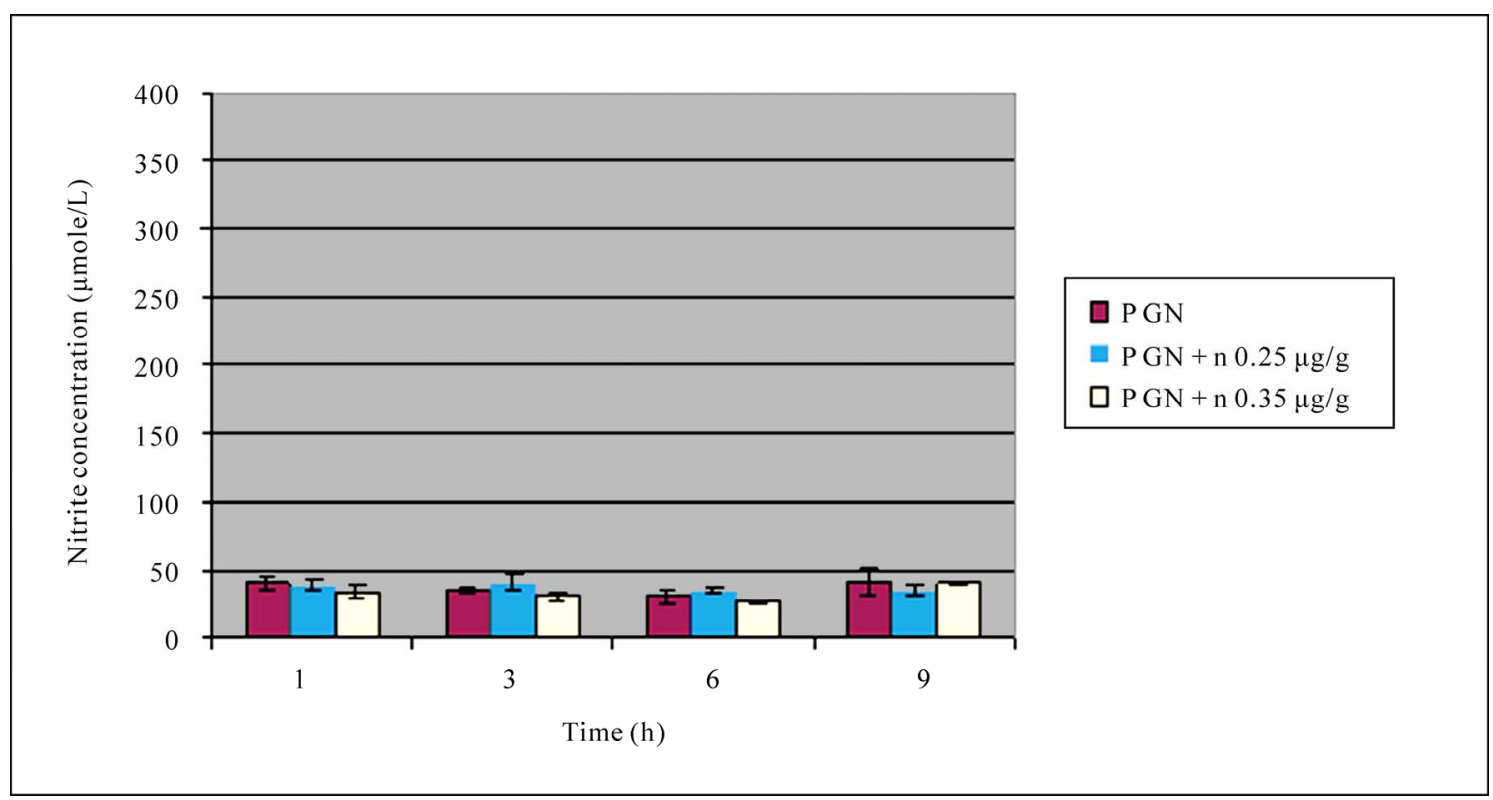

Figure 4. Nitrite levels, reflecting NO levels, at 1, 3, 6 and 9 hours after injection of PGN or PGN with nebivolol (n). Columns represent mean of duplicate analysis and the bars standard deviation of the duplicate analysis. Differences between concentrations of nitrite were considered significant when the means and the standard deviations did not overlap. PGN: peptidoglycan (100 $\mu \mathrm{g} /$ mouse); n: nebivolol.

Understanding the relationship between nebivolol and PGN on NO production machinery is complex due to the interrelationships among NO induction pathways. Some studies have indicated that beta blockers do not interact through the MyD88-dependent or the MyD88-independent pathways and that the MyD88-dependent pathway that leads to NO production after PGN engages TLR2, is unaffected by the administration of beta blockers [46]. Other findings have shown that beta blockers affect PGN through other PGN recognition receptors such as CD14, nucleotide oligomerization domain (Nod)-containing proteins, a family of PGN recognition proteins, and 
PGN-lytic enzymes [47,48].

In conclusion it appears that nebivolol induces the production of NO. When given with LPS in low dose it suppresses LPS-induced production of NO, whereas a high dose at long interval of time enhances this effect. PGN had no significant effect on NO production and nebivolol was without additional effect.

\section{REFERENCES}

[1] Furchgott, R.F., Zawadzki, J.V. (1980) The obligatory role of endothelial cells in the relaxation of arterial smooth muscle by acetylcholine. Nature, 288, 373-376.

[2] Ignarro, L. (1990) Nitric Oxide: A novel transduction mechanism for transcellular communication. Hyper- tension, 16, 477-483.

[3] Hobbs, A., Higgs, A. and Moncada, S. (1999) Inhibition of nitric oxide synthase as a potential therapeutic target. Annual Review Pharmacology Toxicology, 39, 191-220.

[4] Maffei, A. and Lembo, G. (2009) Nitric oxide mechanisms of nebivolol. Therapeutic Advances in Cardiovascular Disease, 10, 1-11.

[5] Falciani, M., Rinaldi, B. D., Agostino, B., Mazzeo, F., Rossi, S. and Nobili, B. (2001) Effects of nebivolol on human platelet aggregation. Journal of Cardiovascular Pharmacology, 38, 922-929.

[6] Ignarro, J., Sisodia, M., Trinh, K., Bedrood, S., Wu, G., Wei, L. and Buga, G. (2002) Nebivolol inhibits vascular smooth muscle cell proliferation by mechanisms involving nitric oxide but not cyclic GMP. Nitric Oxide, 7, 83-90.

[7] Mercanoglu, G., Safran, N., Gungor, M., Pamukcu, B., Uzun, H. and Sezgin, C. (2008) The effects of nebivolol on apoptosis in a rat infarct model. Circulation Journal, 72, 660-670.

[8] Togni, M., Vigorito, F., Windecker, S., Abrecht, L., Wenaweser, P. and Cook, S. (2007) Does the beta-blocker nebivolol increase coronary flow reserve? Cardiovascular Drugs and Therapy, 21, 99-108.

[9] Hancock, C.M. and Walsh, D.A. (2008) Modulation of pain in osteoarthritis: the role of nitric oxide. Clinical Journal of Pain, 24, 353-365.

[10] Szabo, C. and Radi, R. (2007) Peroxynitrite: biochemistry, pathophysiology and development of therapeutics. Nature Reviews Drug Discovery, 6, 662-680.

[11] Mackenzie, I., Rutherford, D. and MacDonald, T. (2008) Nitric Oxide and cardiovascular effects: new insights in the role of nitric oxide for the management of osteoarthritis. Arthritis Research \& Therapy, 10, 2.

[12] Guix, F., Uribesalgo, I., Coma, M. and Munoz, F. (2005) The physiology and pathophysiology of nitric oxide in the brain. Progress in Neurobiology, 76, 126-152.

[13] Raetz, C.R.. (1990) Biochemistry of endotoxin. The Annual Review of Biochemistry, 59, 129-170.

[14] Akira, S. and Takeda, K. (2004) Toll-like receptor signaling. Nature Reviews Immunology, 4, 499-511.

[15] Jiang, Z., Georgel, P., Du, X., Shamel, L., Sovath, S., Mudd, S., Huber, M., Kalis, C., Keck, S., Galanos, C., Freudenberg, M. and Beutler, B. (2005) CD14 is required for MyD88-independent LPS signaling. Nature Immunolog, 6, 565-570.
[16] Kitchens, R.L., Thompson, P.A., O'Keefe, G.E. and Munford, R.S. (2000) Plasma constituents regulate LPS binding to, and release from, the monocyte cell surface. Journal of Endotoxin Research, 6, 477-482.

[17] Mangrella, M., Rossi, F., Fici, F. and Rpssi, F. (1998) Pharmacology of nebivolol. Pharmacological Research, 38, 6 .

[18] Broeders, M., Doevendans, P.A. and Van Der Zee, R. (2000) Nebivolol: A third generation beta-blocker that augments vascular no release. Circulation, 102, 677-684.

[19] Maffei, A., Pardo, A., Carangi, R., Lembo, G., Carullo, P., Poulet, R., Gentile, M. and Vecchione, G. (2007) Nebivolol induces Nitric Oxide release in the heart through inducible Nitric Oxide synthase activation. Hypertension, 50, 652- 656 .

[20] Weiss, R. (2006) Nebivolol: A novel beta-blocker with nitric Oxide-induced vasodilatation. Vascular Health and Risk Management, 2, 303-308.

[21] Veverka, A. and Salinas, J. (2007) Nebivolol in treatment of chronic heart failure. Vascular Health and Risk Management, 3, 647-654.

[22] Agabiti-Rosei, E., Porteri, E. and Rizzoni, D. (2009) Arterial stiffness, hypertension, and rational use of nebivolol. Vascular Health and Risk Management, 5, 353-360.

[23] Zanchetti, A. (2004) Clinical pharmacodynamics of nebivolol. Blood Pressure Supplies, 1, 17-32.

[24] Gupta, S. and Wright, H.M. (2008) Nebivolol: A highly selective beta1-adrenergic receptor blocker that causes vasodilation by increasing Nitric Oxide. Cardiovascular Therapeutics, 26, 189-202.

[25] Papademetriou, V. (2008) Beta blockers in management of hypertension: Focus on nebivolol. Expert Review of Cardiovascular Therapy, 6, 471-479.

[26] Judy, W.M. Cheng, B.S. (2009) Nebivolol: A third-generation P-Blocker for hypertension. Clinical Therapeutics, 31, 3 .

[27] Ladage, D., Brixius, K., Hoyer, H., Steingen, C., Wesseling, A. and Malan, D. (2006) Mechanisms underlying nebivolol-induced endothelial Nitric Oxide synthase activation in human umbilical vein endothelial cells. Clinical and Experimental Pharmacology and Physiology, 33 , 720-724

[28] Ignarro, J., Sisodia, M., Trinh, K., Bedrood, S., Wu, G., Wei, L. and Buga, G. (2002) Nebivolol inhibits vascular smooth muscle cell proliferation by Mechanisms involving Nitric Oxide but not cyclic GMP. Nitric Oxide, 7, 83-90.

[29] Maffei, A. and Lembo, G. (2009) Nitric Oxide mechanisms of nebivolol. Therapeutic Advances in Cardiovascular Disease, 10, 1-11.

[30] Togni, M., Vigorito, F., Windecker, S., Abrecht, L., Wenaweser, P. and Cook, S. (2007) Does the beta-blocker nebivolol increase coronary flow reserve? Cardiovascular Drugs and Therapy, 21, 99-108.

[31] Maffei, A., Vecchione, C., Aretini, A., Poulet, R., Bettarini, U. and Gentile, M.T. (2006) Characterization of nitric oxide release by nebivolol and its metabolism. American Journal of Hypertension, 19, 579-586.

[32] Supajatura, V., Ushio, H., Nakao, A., Akira, S., Okumura, K., Ra, C. and Ogawa, H. (2002) Differential responses of mast cell Toll-like receptors 2 and 4 in allergy and in- 
nate immunity. The Journal of Clinical Investigation, 109, 1351-1359.

[33] Tzemos, N., Lim, P.O. and MacDonald, T.M. (2001) Nebivolol reverses endothelial dysfunction in essential hypertension. A randomized, double-blind, crossover study. Circulation, 104, 511-14.

[34] MacMicking, J.D., Nathan, C., Hom, G., Chartrain, N., Fletcher, D.S., Trumbauer, M., Stevens, K., Xie, Q.W., Sokol, K. and Hutchinson, N. (1997) Altered responses to bacterial infection and endotoxic shock in mice lacking inducible nitric oxide synthase. Cell, 8, 641-650.

[35] Cobb, J.P. and Danner, R.L. (1996) Nitric oxide and septic shock. The Journal of the American Medical Association, 275, 1192-1196.

[36] Akira, S. and Takeda, K. (2004) Toll-like receptor signaling. Nature Reviews Immunology, 4, 499-511.

[37] Bagchi, A., Herrup, E., Warren, E., Trigilio, J., Shin, H., Valentine, C. and Hellman, J. (2007) MyD88-dependent and MyD88-independent pathways in synergy, priming, and tolerance between TLR agonists. The Journal of Immunology, 178, 1164-1171.

[38] Kawai, T., Adachi, O., Ogawa, T., Takeda, K. and Akira. S. (1999) Unresponsiveness of MyD88-deficient mice to endotoxin. Immunity, 11, 115-122.

[39] Kreutz, M., Ackermann, U., Hauschildt, S., Krause, S.W., Riedel, D., Bessler, W. and Andreesen, R. (1997) A comparative analysis of cytokine production and tolerance induction by bacterial lipopeptides, lipopolysaccharides and Staphyloccous aureus in human monocytes. Immunology, 92, 396-401.

[40] Poltorak, A., He, X., Smirnova, I., Liu, M.Y., Huffel, C.V., Du, X., Birdwell, D., Alejos, E., Silva, M. and Galanos, C. (1998) Defective LPS signaling in C3H/HeJ and $\mathrm{C} 57 \mathrm{BL} / 10 \mathrm{ScCr}$ mice: mutations in Tlr4 gene. Science, 282, 2085-2088.

[41] Guix, F., Uribesalgo, I., Coma, M. and Munoz, F. (2005) The physiology and pathophysiology of nitric oxide in the brain. Progress in Neurobiology ,76, 126-152

[42] Manni, M. and Maestroni, G. (2008) Sympathetic nervous modulation of the skin innate and adaptive immune response to peptidoglycan but not lipopolysaccharide: Involvement of $\beta$-adrenoceptors and relevance in inflamematory diseases. Brain, Behavior, and Immunity, 22, 80-88.

[43] Fahmi, H., Ancuta, P. and Chaby, R. (1996) Preexposure of mouse peritoneal macrophages to lipopolysaccharide and other stimuli enhances nitric oxide response to secondary stimuli. Inflammation Research, 45, 347-356.

[44] Ida, A.J., Giebelen, Masja, L., Mark, C.D., Joost, C.M., Meijers, M.L., Christian, D., Sonja, von A. and Tom van der P. (2008) Endogenous adrenergic receptors inhibit LPS-induced pulmonary cytokine release and coagulation. AJRCMB Articles in Press.

[45] Arai, K., Wood, J.P. and Osborne, N.N. (2003) Betaadrenergic receptor agonists and antagonists counteract LPS-induced neuronal death in retinal cultures by different mechanisms. Brain Research, 985, 176-86.

[46] Palsson-McDermott, E. and O’Neill, L. (2004) Signal transduction by the lipopolysaccharide receptor, Toll-like receptor-4. Immunology, 113, 153-162.

[47] Dziarski, R. and Gupta, D. (2005) Peptidoglycan recognition in innate immunity. Journal of Endotoxin Research, 11, 304-310.

[48] Dziarski, R. and Gupta, D. (2005) Staphylococcus aureus peptidoglycan is a toll-like receptor 2 activator: A reevaluation. Infection and Immunity, 73, 5212-5216. 